\title{
A heat transfer model of a PV panel integrated with a "Rainscreen Cladding System"
}

\author{
D. Knera \& D. Heim \\ Lodz University of Technology, Poland
}

\begin{abstract}
The numerical model presented in the paper was formulated to describe heat transfer in a PV panel integrated with an opaque ventilated facade "Rainscreen Cladding System". It was assumed that the external layer is not airtight and is adjacent to the air gap behind the PV panels. This means that air flows from both sides of the panel, but inside and outside the air speed and temperature are different.

Dynamic, numerical methods are usually dedicated to describe the heat transfer in the whole building domain, including multilayer external wall construction. The results of specific panel temperature and incident solar radiation determine the electricity generated by the PV cell.

As an example of the heat transfer analysis the numerical simulations were performed to examine the effect of air flow in a cavity on the temperature of the PV panel. The geometry and dimensions of the wall system were assumed as a constant. The optimum air flow speed was determined by the magnitude of the cracks between panels. Hourly values of weather parameters such as air temperature, solar radiation and wind speed were used to determine heat and mass flow as well as the temperature of the panel during the whole year. The results can be applied to determine the efficiency of solar radiation converted into electricity including changeable weather conditions and the temperature of the PV cell.
\end{abstract}

Keywords: BIPV, heat transfer, air flow, simulation, efficiency.

\section{Introduction}

Building Integrated Photovoltaic (BIPV) is one of the most promising technologies of solar energy utilization in buildings. This system seems to be very suitable for all buildings types, both residential and public once. PV 
systems are often integrated with facades as an external layer and play a significant role in heat transfer of external wall. Nowadays, more and more easily mounted solutions of photovoltaic façade appear on the market. One of them is connected with cladding systems, which allow for arrangement of photovoltaic elements in different ways.

The aim of this study is analysis of the heat exchange at the external and internal surfaces of the photovoltaic façade integrated into building as a ventilated "Rainscreen Cladding System".

\section{Building integrated photovoltaic}

The main concept of the BIPV is replacing traditional elements of building envelope by active system consisting of photovoltaic module. Jelle et al. [1] described four main types of BIPV due to the position of photovoltaic cells and integration with sloped roofs, flat roofs, facades or shading systems. Moreover, photovoltaic elements can be opaque or transparent.

Very attractive solution for office buildings is photovoltaic integrated into facade. Quesada et al. [2,3] give an extensive review of existing types of opaque and transparent solar facades with division into active and passive types.

Regardless of the previous mentioned types of BIPV, all photovoltaic systems are susceptible to the influence of many environmental factors, such as solar radiation, temperature, angle of incidence of solar radiation and spectral distribution. Cell temperature is one of the most significant parameter because of the effect on efficiency of the photovoltaic conversion (Heim [4]). Therefore, temperature stability of the PV elements is very important.

Additionally, negative impact of the photovoltaic facades integrated with buildings located in the city centre has urban heat island effect. Urban changes and high density of buildings caused accumulation of heat and impeded the natural circulation of air. Consequently, the metropolitan area is significantly warmer in comparison to the surroundings (Barlag and Kuttler [5]).

\section{Modelling capabilities of existing simulation programs}

\subsection{Modelling of building integrated photovoltaic components}

Appropriate modelling of BIPV system in energy performance simulation tool is very complex and challenging. Building integrated photovoltaic components were implemented into ESP-r by Clarke and Kelly [6] as a multi-layer construction model. Photovoltaic facade consisted of outer glazing, PV element, resin binder and back sheet glazing. Photovoltaic material was formed as a layer of number of solar cells. The PV properties were determined in form of specific components using 'special material' database. Moreover, the photovoltaic material was defined as a hybrid thermal/electrical component. Solar radiation absorbed at the surface of the photovoltaic material is converted into heat and electrical energy simultaneously. Current-voltage characteristic of each solar cell was determined by equivalent one-diode circuit model. 


\subsection{Modelling air flow - nodal network}

The air flow through the gap behind the photovoltaic can be determined using the nodal network method. The basic elements of this method are nodes, internal and external. Each of them is described by temperature and pressure. Internal nodes with unknown pressure represent particular rooms or parts of rooms defined as one zone. External nodes are connected with exterior environment and their pressure is determined by wind. Components like cracks, openings or ducts, located between the nodes define the network properties. Due to the pressure differences between the nodes there is flow of the air

The nodal network is limited to the calculation of the system of nonlinear equations (Clarke [7]).

\section{Heat exchange model}

The presented paper focuses on the heat transfer through the photovoltaic facade integrated with building structure in a form of "Rainscreen Cladding System". Heat exchange processes on the external and internal surfaces of the photovoltaic façade were considered in the analysis. Heat exchange at the external surface was determined by changing external environmental conditions: air temperature $\left(T_{e}\right)$, solar radiation $\left(I_{s}\right)$, wind speed $\left(v_{e}\right)$ and direction $(\gamma)$. At the internal surface, heat exchange processes were determined by the differences between surface $\left(T_{s i}\right)$ and cavity air temperatures $\left(T_{i}\right)$ as well as air speed in a gap $\left(v_{i}\right)$.

\subsection{Solar thermal processes}

Solar radiation is one of the most significant weather parameter affecting the building energy performance. Depending on the construction and optical properties of the building envelope the solar radiation heat gains distribution is different, fig. 1 . In a case of the opaque façade, radiation incident on the surface is reflected $\left(I_{\rho}\right)$ and absorbed $\left(I_{\alpha}\right)$. In case of the building integrated photovoltaic absorbed solar radiation is converted partially into heat $\left(I_{\alpha, H}\right)$ and electricity $\left(I_{\alpha, E}\right)$. Considering transparent and semi-transparent envelope of the building solar radiation can by additionally transmitted $\left(I_{\tau}\right)$.
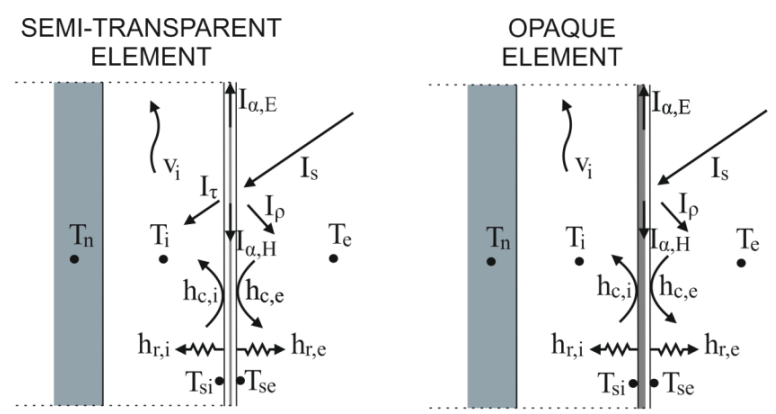

Figure 1: Solar processes in semi-transparent and opaque photovoltaic facades. 


\subsection{Heat transfer}

\subsubsection{External surface}

Heat exchange processes at the external surface can be described by three heat fluxes: the ground and sky long wave radiation, convection and absorptivity of short wave radiation, eqn (1).

$$
\varepsilon_{n} \sigma\left[F_{s-g}\left(T_{g}^{4}-T_{s e}^{4}\right)+F_{s-s k y}\left(T_{s k y}^{4}-T_{s e}^{4}\right)\right]+h_{c, e}\left(T_{s e}-T_{e}\right)+q_{s o l}=-\lambda \frac{\partial T}{\partial x}
$$

where:

$\varepsilon_{n}$ - surface long wavelength emissivity,

$\sigma-$ Stefan-Boltzmann constant,

$F_{s-g}$ - view factor from the surface to the ground,

$F_{s-s k y}-$ view factor from the surface to the sky,

$T_{g}$ - ground temperature $[\mathrm{K}]$,

$T_{\text {sky }}$ - effective sky temperature [K],

$T_{s e}$ - external surface temperature $[\mathrm{K}]$,

$T_{e}$ - external air temperature $[\mathrm{K}]$,

$h_{c, e}-$ external convective heat transfer coefficient $\left[\mathrm{W} /\left(\mathrm{m}^{2} \cdot \mathrm{K}\right)\right]$,

$q_{\text {sol }}-$ absorbed solar heat flux $\left[\mathrm{W} / \mathrm{m}^{2}\right]$,

$\lambda$ - thermal conductivity $[\mathrm{W} /(\mathrm{m} \cdot \mathrm{K})]$.

The external convective heat transfer coefficient is determined by the McAdams formula implemented into ESP-r in a form of linear function of the local wind speed $\left(V_{l o c}\right)$, eqn (2) (Mirsadeghi et al. [8]).

$$
h_{c, e}=3 V_{l o c}+2.8 \text {, }
$$

Solar heat flux absorbed by the BIPV surface is converted into heat $\left(I_{\alpha, H}\right)$ and electrical energy $\left(I_{\alpha, E}\right)$ according to the efficiency of the photovoltaic elements, eqn (3) (Clarke [7]).

$$
q_{s o l}=q_{A, H}+q_{A, E}
$$

\subsubsection{Internal surface}

In order to describe heat exchange processes at internal surface, long wavelength radiation given off by parallel wall and convection at the internal surface are considered, eqn (4).

$$
\varepsilon_{n} \sigma F_{n}\left(T_{n}^{4}-T_{s i}^{4}\right)+h_{c, i}\left(T_{p}-T_{s i}\right)=-\lambda \frac{\partial T}{\partial x}
$$


where:

$F_{n}$ - view factor from the surface to the wall,

$T_{g}$ - wall temperature $[\mathrm{K}]$,

$T_{s i}$ - internal surface temperature $[\mathrm{K}]$,

$h_{c, i}$ - internal convective heat transfer coefficient $\left[\mathrm{W} /\left(\mathrm{m}^{2} \cdot \mathrm{K}\right)\right]$,

$T_{p}$ - air temperature in the air gap [K].

Natural convection at internal surface can be determined by general expression of the convective heat transfer coefficient implemented into ESP-r for both vertical and horizontal surfaces. Considering the factors appointed for the vertical surface, the internal convective heat transfer coefficient can be calculated by eqn (5) (Clarke [7]).

$$
h_{c, i}=\left\{\left[1.5\left(\frac{\Delta T}{d}\right)^{1 / 4}\right]^{6}+\left[1.23(\Delta T)^{1 / 3}\right]^{6}\right\}^{1 / 6}
$$

where:

$\Delta T$ - the surface-to-air temperature difference $[\mathrm{K}]$,

$d$ - the characteristic dimension given by the surface height [m].

\section{Problem definition}

The effects of temperature and solar radiation on conversion efficiency of traditional stand alone PV panel are well known and were described by many authors during last decades (Thevenard [9]). However, considering the building integrated photovoltaic two additional factors are significant:

- $\quad$ the slope of PV panel is determined by a slope of building element, e.g. roof, wall, etc.,

- ventilation of the back surface of PV panel is worse in comparison with freestanding PV.

The air cooling potential of PV system depends on temperature differences between PV surface temperature and external air temperature. The cooling effectiveness is a dependent on the temperature difference and convection heat transfer coefficient. The normal distribution of air and surface temperature is presented in fig. 2. It can be noted that total differences between maximum values of presented functions is $7.16 \mathrm{~K}$ for transparent and $11.08 \mathrm{~K}$ for opaque construction.

The possible changes in PV efficiency can be estimated based on results presented in fig. 3. Maximum deviations of PV efficiency caused by temperature are not higher than $2 \%$. Considering the normal distribution in fig. 4 the bigger density of probability can be noticed for the range of the incident irradiation from 50 up to $250 \mathrm{~W} / \mathrm{m}^{2}$. The effect of the solar radiation and temperature on $\mathrm{PV}$ efficiency is comparable for this scope and is approximately $2 \%$. For higher range $\left(250 \div 500 \mathrm{~W} / \mathrm{m}^{2}\right)$ differences in efficiency due to the solar radiation are slighter, about $1 \%$. 


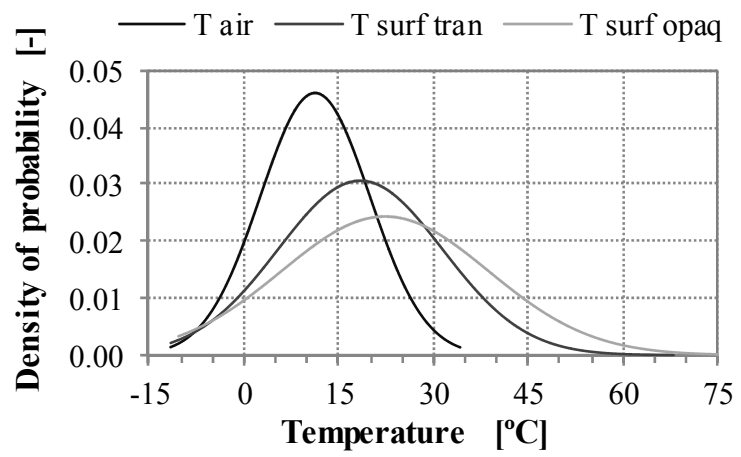

Figure 2: The normal distribution of ambient air temperature and surface temperature behind semi-transparent or opaque photovoltaic panel during whole year (daytime only).

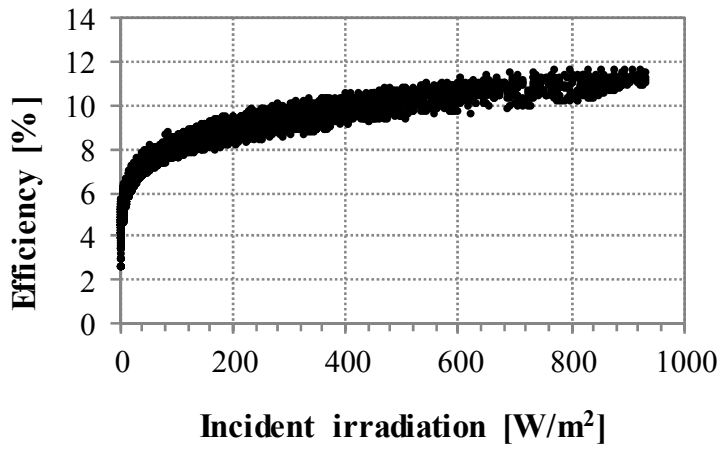

Figure 3: Photovoltaic panel efficiency vs. the incident irradiation.

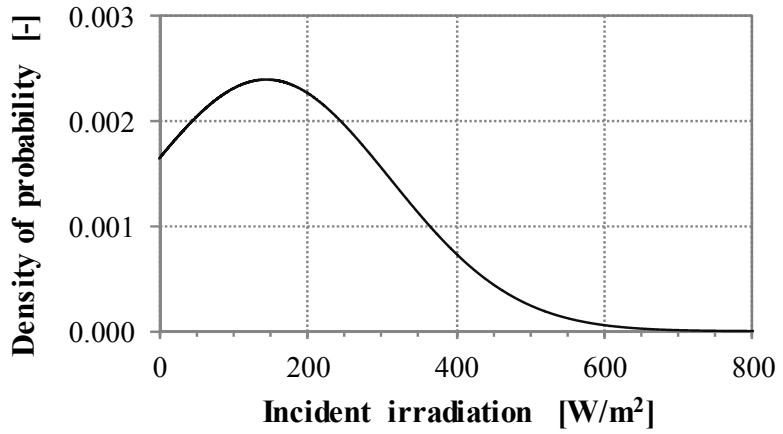

Figure 4: The normal distribution of incident irradiation at the east oriented façade during whole year. 


\section{Case study}

The paper presents a study of the heat transfer for a building integrated photovoltaic façade. Analysis was conducted for office building located in the city centre and moderate climatic conditions. Analysed facade was oriented on the east. Simulations were carried out for Typical Meteorological Year. In order to obtain detailed results, analysis was performed throughout the whole year with 15 minutes time step.

\subsection{Geometry}

Analysis was performed for one segment of the whole building. Analysed model consisted of two zones: building space and air cavity. Former zone with dimensions: $3.0 \times 6.0 \times 3 \mathrm{~m}$ (width $\times$ depth $\times$ height) was as a single office room. Photovoltaic façade was modelled as a second, very narrow $(0.1 \mathrm{~m}$ depth only) separate zone. Three different cases were analysed taking into account different techniques of façade ventilation, fig. 5. Case A presents the simplest, reference model, without any air flow, fig. 5a. Case B was established as a slightly ventilated façade. Simple air flow network was assumed with one internal node representing whole air gap and connected with exterior by four cracks situated on the facade edges, fig. 5b. Case $\mathrm{C}$ represents the most complicated, highly ventilated facade system, fig. 5c. Air cavity was divided on 12 combined control volumes represented by individual nodes and a system of possibly connections (by two types of cracks) including external nodes.
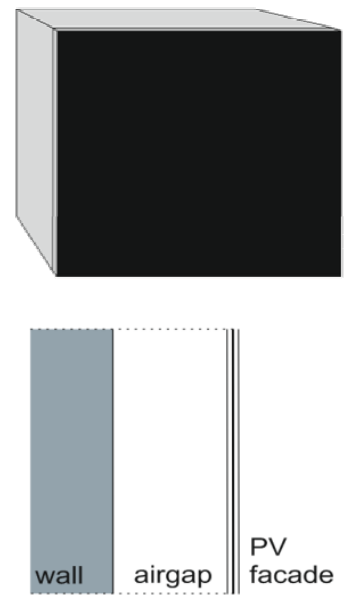

a)
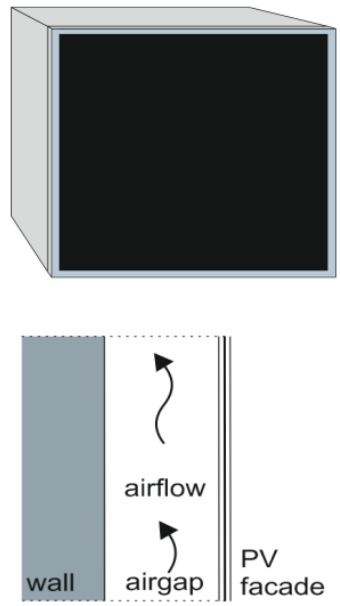

b)
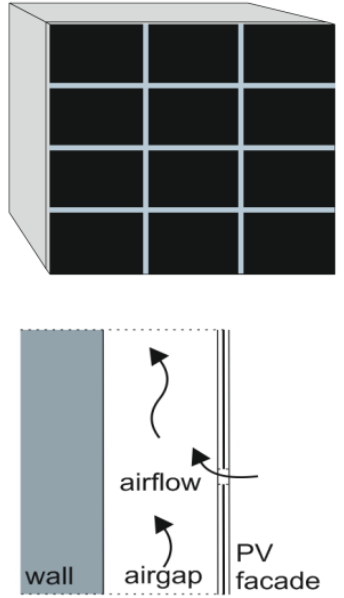

c)

Figure 5: Constructions of analysed facades systems: a) non-ventilated, b) slightly ventilated, c) highly ventilated. 


\subsection{BIPV construction}

Building integrated photovoltaic components implemented into ESP-r consist of three layers: outer glazing, PV assigned to resin binder and back sheet glazing. Analysis was performed for two different types of back sheet glazing. The first one was implemented as semi-transparent glazing (I) and the second on as opaque element (II), fig. 6. Optical properties of the outer glazing and resin binder are the same for both constructions of the photovoltaic facade.

Electrical characteristics were assumed according to specification of the modular photovoltaic element, StoVentec ARTline Inlay, proposed by Sto Company as a ventilated "Rainscreen Cladding System":

- Open circuit voltage: $44.02[\mathrm{~V}]$;

- $\quad$ Short circuit current: $2.5[\mathrm{~A}]$;

- Voltage at maximum power point: 35 [V];

- Current at maximum power point: 2.3 [A].

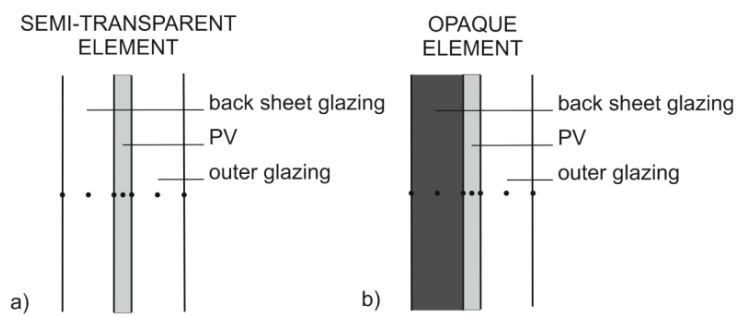

Figure 6: Construction of analysed photovoltaic partition: a) semitransparent element, b) opaque element.

\section{Results}

Results presented in the paper were divided into three parts. First, analysis of the surface temperature was performed considering the construction of the photovoltaic layer. Subsequently, the influence of the incident solar radiation on the efficiency of photovoltaic façade was analysed. Last part concerns the relation between air velocity in the air gap and climate conditions like temperature, incident radiation, wind speed and direction.

\subsection{Internal surface temperature}

The internal surface temperatures for semi-transparent and opaque highly ventilated photovoltaic facade are presented in fig. 7 and fig. 8. In order to effectively display detailed results, graphs of the temperature were limited to the typical summer (11.07-17.07) and winter (18.01-24.01) week. It can be noticed that internal surface temperature for opaque elements is higher than for semi-transparent element in both periods of time. In case of opaque facade heat flux absorbed by the back sheet is high and caused increase of the surface temperature. 


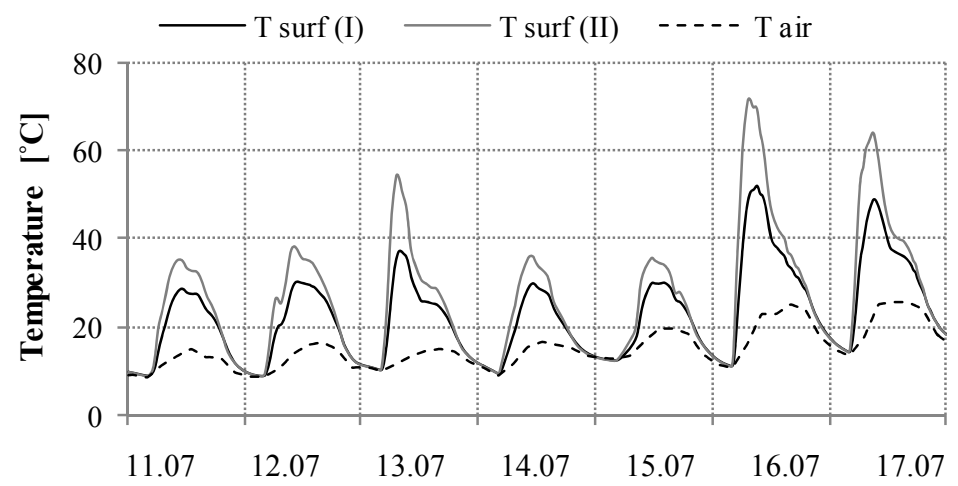

Figure 7: Internal surface temperature for semi-transparent and opaque highly ventilated photovoltaic facade for typical summer week.

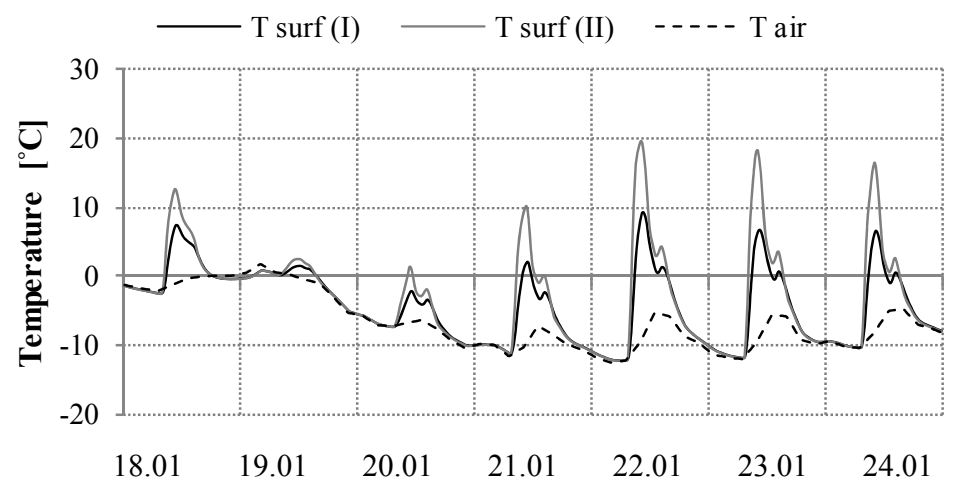

Figure 8: Internal surface temperature for semi-transparent and opaque highly ventilated photovoltaic facade for typical winter week.

\subsection{Efficiency}

Analysis of the efficiency of the photovoltaic façade was performed for the range of the incident irradiation from $100 \mathrm{~W} / \mathrm{m}^{2}$ up to $600 \mathrm{~W} / \mathrm{m}^{2}$. Lower limit was not considered due to the insufficient electrical energy performance of photovoltaic elements while the incident solar radiation is below $100 \mathrm{~W} / \mathrm{m}^{2}$. Whereas the upper limit is caused by the small number of hours during analysed period when the incident radiation exceeds $600 \mathrm{~W} / \mathrm{m}^{2}$. Graph in the fig. 9 presents results and trend line obtained for opaque, highly ventilated façade. It can be noticed that the maximum range of the efficiency because of the incident radiation is equal $\Delta \eta_{\max }\left(I_{s}\right)=2.54 \%$. However, divergences of the obtained results caused by the influence of the PV surface temperature are also significant. Deviations reach $\Delta \eta_{\max }\left(T^{+}\right)=0.84 \%$ as the upper limit and $\Delta \eta_{\max }\left(T^{-}\right)=1.01 \%$ as a lower limit for a total of $\Delta \eta_{\max }(T)=1.85 \%$. 


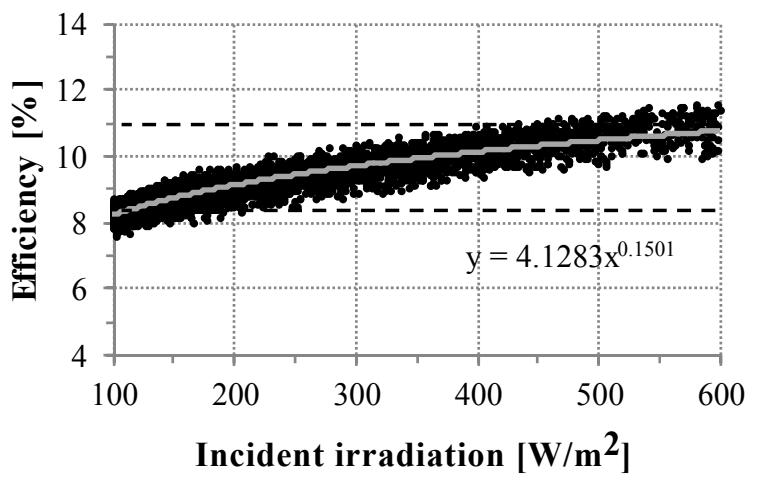

Figure 9: Photovoltaic efficiency vs. incident irradiation for opaque, highly ventilated PV façade.

\subsection{Air flow}

Velocity of the air passing through the air gap depends on climatic conditions like ambient air temperature, incident solar irradiation, wind speed and direction. Wind speed has significant influence when its direction is perpendicular to façade $\left( \pm 30^{\circ}\right)$. Moreover, a construction of the photovoltaic façade, amount and location of the cracks and openings has also significant influence on airflow rate. The air velocity for slightly and highly ventilated façade is presented in the fig. 10. Air velocity both for inlet and outlet of slightly ventilated façade (fig. 5b) is lower than for highly ventilated façade (fig. 5c). Exception is the time during the day when air velocity for both cases suddenly increases. The shape of the graphs for all cases is similar and indicates substantial air velocity dependence from the incident irradiation, especially during sunny day of 20.06 (fig 10 and fig. 12). On the other days relation between air velocity and wind speed is also noticeable (fig 10 and fig. 11).

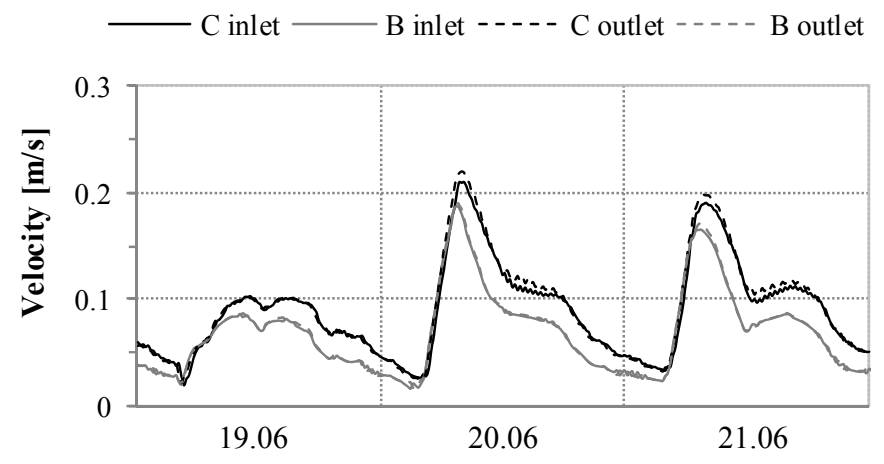

Figure 10: Air velocity for slightly and highly ventilated opaque photovoltaic facade for selected days in June. 


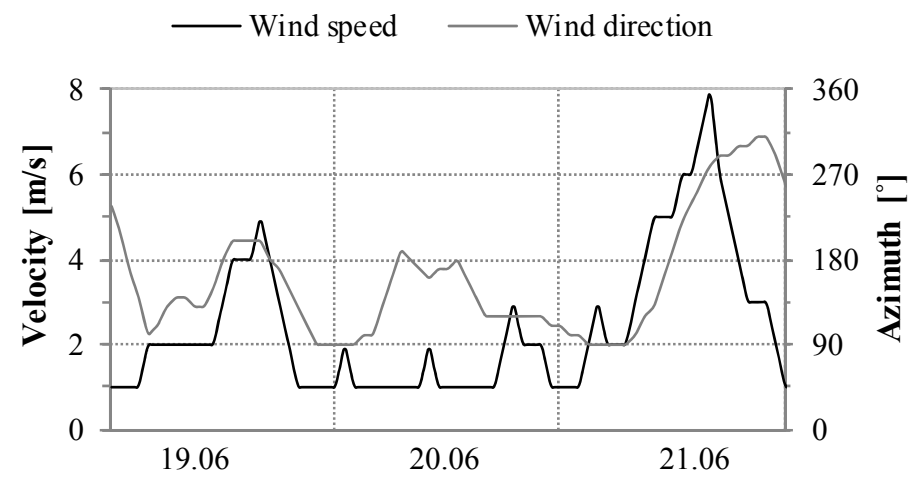

Figure 11: Wind speed and direction for selected days in June.

- Air temperature - Incident irradiaton

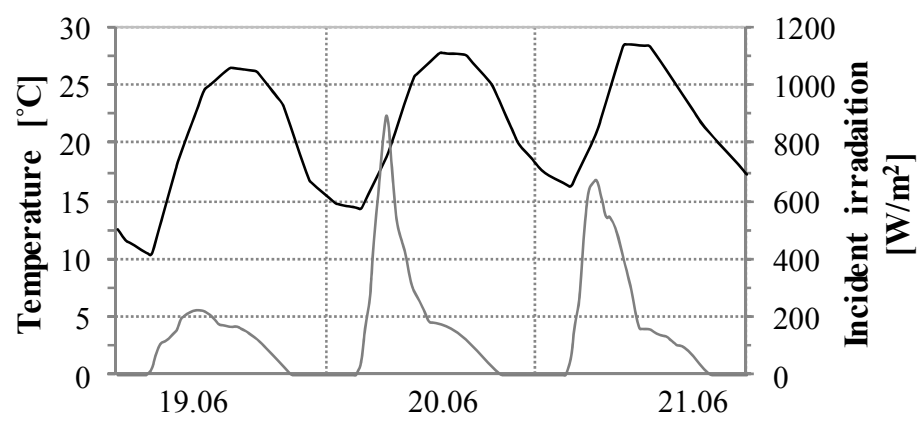

Figure 12: Air temperature and incident irradiation at the east oriented facade for selected days in June.

\section{Summary}

The heat exchange at the both, external and internal surfaces of the photovoltaic ventilated façade was analyzed in the paper. Study was performed for semi-transparent and opaque photovoltaic element and three constructions of the ventilation air gap. An opaque partition of the façade causes higher surface temperature, and consequently decreases of the efficiency of photovoltaic panel. However, high ventilation of the air gap reduces surface temperature of the PV panel and improves their efficiency. Air velocity in the air gap increases with the rise of the solar irradiation on the façade. Moreover a wind speed affecting directly on the façade has also influence on the ventilation rate in air gap. Therefore efficiency of the building integrated photovoltaic is very complex issue and strongly depends on climatic conditions. 


\section{Acknowledgement}

This work was funded by The National Centre for Research and Development as part of the project entitled: "Promoting Sustainable Approaches Towards Energy Efficiency in Buildings as Tools Towards Climate Protection in German and Polish Cities: developing facade technology for zero-emission buildings" (acronym: GPEE).

\section{References}

[1] Jelle B. P., Breivik C., Røkenes H. D., Building integrated photovoltaic products: A state-of-the-art review and future research opportunities. Solar Energy Materials \& Solar Cells, (100), pp. 69-96, 2012.

[2] Quesada G., Rousse D., Dutil Y., Badache M., Hallé S., A comprehensive review of solar facades. Opaque solar facades. Renewable and Sustainable Energy Reviews, (16), pp. 2820-2832, 2012.

[3] Quesada G., Rousse D., Dutil Y., Badache M., Hallé S., A comprehensive review of solar facades. Transparent and translucent solar facades. Renewable and Sustainable Energy Reviews, (16), pp. 2643-2651, 2012.

[4] Heim D., The simultaneous effect of the operating temperature and solar radiation of the efficiency of photovoltaic panels, Archives of civil engineering, LVII, 3, 2011.

[5] Barlag A.B., Kuttler W., The significance of country breezes for urban planning. Energy and Building, (15-16), pp. 291-297, 1990/91.

[6] Clarke J.A., Kelly N.J., Integrating power flow modelling with building simulation. Energy and Building, (33), pp. 333-340, 2001.

[7] Clarke J.A., (eds). Energy Simulation in Building Design (2nd edition), Butterworth-Heinemann, 2001.

[8] Mirsadeghi, M., Cóstola, D., Blocken, B. \& Hensen, J.L.M., Review of external convective heat transfer coefficient models in building energy simulation programs: Implementation and uncertainty. Applied Thermal Engineering, (56), pp. 134-151, 2013.

[9] Thevenard D., Review and recommendations for improving the modelling of building integrated photovoltaic systems. Proc. of the $9^{\text {th }}$ International IBPSA Conference, Montreal, Canada, August 15-18, 2005. 